\title{
Analisis Nonlinear Pengaruh Lokasi dan Panjang Pengaku Longitudinal Terhadap Lipat Web Balok Baja
}

\author{
Fenita Adina Santoso ${ }^{1, *}$, Bambang Suryoatmono ${ }^{1}$ \\ Jurusan Teknik Sipil, Universitas Katolik Parahyangan, Bandung ${ }^{1}$ \\ Koresponden*,Email:fenitaadina@gmail.com
}

\begin{tabular}{lll}
\hline & Info Artikel & Abstract \\
\hline Diajukan & 10 Juli 2019 & Web crippling at a beam support is web buckling caused by vertical support reaction transferred \\
Diperbaiki & 15 Juli 2019 & by bottom flange to the web. Longitudinal stiffeners are often used to avoid web crippling. The \\
Disetujui & aim of this research is to obtain the optimum location and length of longitudinal stiffener. This \\
& research utilizes finite element analysis and considers nonlinear material and second order \\
& effect. The analysis consists of both linear and nonlinear buckling analyses. The first buckling \\
& mode of linear analysis is used as initial imperfection in the nonlinear buckling analysis. The \\
& location and length of longitudinal stiffener are varied to obtain each web crippling strength. \\
& By using stepwise regression analysis, an equation to predict web crippling strength is obtained. \\
& The optimum vertical location and length of longitudinal stiffener were obtained in this \\
& research, namely 0.32 of web height measured from the top of the bottom flange and 0.62 of \\
Kalf of the beam span.
\end{tabular}

\section{Abstrak}

Lipat web di tumpuan balok adalah tekuk web yang disebabkan reaksi vertikal tumpuan yang disalurkan oleh flens bawah ke web. Pengaku longitudinal sering digunakan untuk mencegah lipat web. Tujuan penelitian ini adalah mendapatkan lokasi dan panjang pengaku longitudinal yang optimum. Penelitian ini menggunakan analisis elemen hingga dan memperhitungkan kenonlinearan material dan efek orde kedua. Analisis terdiri dari analisis tekuk linear dan nonlinear. Modus tekuk pertama analisis linear digunakan sebagai ketidaksempurnaan awal dalam analisis tekuk nonlinear. Lokasi dan panjang pengaku longitudinal divariasikan untuk mendapatkan kekuatan lipat web. Dengan menggunakan analisis regresi bertatar, persamaan untuk memprediksi kekuatan lipat web didapatkan.

Kata kunci: pengaku longitudinal, lipat Lokasi vertikal dan panjang pengaku longitudinal yang optimum didapatkan yaitu 0,32 web, analisis tekuk nonlinear tinggi web diukur dari atas flens bawah dan 0,62 setengah bentang balok.

\section{Pendahuluan}

Gelagar pelat banyak digunakan pada struktur jembatan karena bentangnya yang panjang dan kebutuhan akan kekuatan lentur dan geser yang tinggi. Gelagar pelat pada umumnya memiliki web yang tidak kompak sehingga dibutuhkan pengaku-pengaku untuk mencegah kegagalan pada web, yaitu leleh web (web yielding) dan lipat web (web crippling) di area lokal akibat beban tekan vertikal terpusat yang disalurkan melalui flens. Pengaku tersebut dapat berupa pengaku transversal dan pengaku longitudinal. Pengaku transversal dapat digunakan untuk memperkuat web sehingga lipat web tidak terjadi, tetapi penggunaan pengaku transversal dihindari untuk alasan-alasan praktis dan ekonomis[1].

Penelitian mengenai kekuatan lipat web gelagar pelat telah dilakukan. Roberts[2] mengembangkan suatu model kegagalan untuk memperkirakan beban ultimit pada suatu gelagar I langsing yang mengalami beban terpusat. Model ini menggambarkan ragam kegagalan plastis pada flens atas yang dibebani dari atas dan sebagian web di bawahnya.
Empat sendi plastis digunakan untuk memodelkan ragam kegagalan ini dan efek lipat web terjadi di panel web tersebut. Menurut Graciano dan Edlund[3] pengaku longitudinal dapat meningkatkan kekuatan penampang terhadap lipat web di daerah lapangan apabila lokasi vertikal pengaku tersebut, diukur dari tepi bawah flens atas, kurang dari $40 t_{w}$, dengan $t_{w}$ adalah tebal web. Menurut Salmon[4], pengaku longitudinal untuk web yang mengalami geser saja seharusnya diletakkan pada setengah tinggi web sedangkan untuk kombinasi geser dan lentur, pengaku tersebut sebaiknya diletakkan di antara $h / 5$ sampai $h / 2$, dengan $h$ adalah tinggi web. Loaiza[5] melakukan uji eksperimental kekuatan lipat web gelagar pelat dengan pengaku longitudinal yang hasilnya dibandingkan dengan persamaan lipat web tanpa pengaku di AISC 360-16[6]. Berdasarkan pengujian pada 45 benda uji didapat rasio rata-rata antara uji eksperimental dengan persamaan AISC adalah 1,16.

Penelitian-penelitian tersebut mempelajari kekuatan lipat web dengan pengaku longitudinal pada posisi yang jauh dari 
tumpuan. Pada makalah ini, dianalisis pengaruh lokasi vertikal dan panjang pengaku longitudinal gelagar pelat di daerah tumpuan yang mengalami gaya geser. Tujuannya adalah menentukan lokasi dan panjang pengaku longitudinal yang optimum dengan mempertimbangkan faktor-faktor nonlinear serta menghasilkan persamaan untuk mencari faktor perbesaran kekuatan lipat web untuk variasi lokasi vertikal dan panjang pengaku longitudinal. Faktor perbesaran tersebut diharapkan dapat digunakan sebagai faktor pengali persamaan lipat web tanpa pengaku yang terdapat di dalam AISC 360-16[6].

\section{Metode}

\subsection{Pemodelan}

Penelitian dilakukan dengan melakukan pemodelan pada perangkat lunak komersial ANSYS Workbench. Tipe elemen yang digunakan di dalam analisis elemen hingga adalah shell (SHELL181) dengan 4 nodal tiap elemen dan enam derajat kebebasan di setiap nodal yaitu translasi dalam arah sumbu $\mathrm{X}, \mathrm{Y}, \mathrm{Z}$ dan rotasi terhadap sumbu X, Y, dan Z. Geometri gelagar pelat adalah tinggi web $(h) 570 \mathrm{~mm}$, lebar flens $\left(b_{f}\right)$ $300 \mathrm{~mm}$, tebal web $\left(t_{w}\right) 5 \mathrm{~mm}$, dan tebal flens $\left(t_{f}\right) 15 \mathrm{~mm}$ seperti pada Gambar 1. Lokasi pengaku longitudinal divariasikan dengan rasio $\left(b_{l} / h\right)$ sebesar $0,20,0,30,0,40$, 0,50 , dan 0,60 . Variabel $b_{l}$ adalah jarak vertikal dari tepi atas flens bawah ke as pengaku longitudinal. Panjang pengaku longitudinal divariasikan dengan rasio $\left(l_{s t} /(0,5 l)\right)$ sebesar $0,20,0,40,0,60,0,80$, dan 1,00 dengan $l_{s t}$ adalah panjang pengaku longitudinal dan $l$ adalah panjang bentang gelagar pelat.

Material yang digunakan adalah baja dengan tegangan leleh $F_{y} 250 \mathrm{MPa}$ dan modulus elastisitas $200 \mathrm{GPa}$. Rasio Poisson yang digunakan adalah 0,3 . Kurva tegangan-tegangan yang digunakan adalah elastic perfectly plastic seperti pada Gambar 2. Kurva yang sama digunakan untuk tarik dan tekan. Tegangan sisa yang mungkin ada pada gelagar pelat tidak dimodelkan.

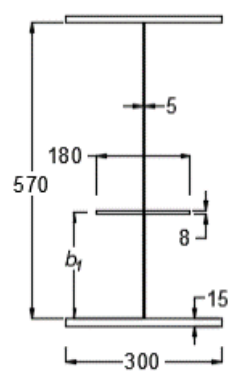

Pembebanan pada struktur berupa beban terbagi rata yang diaplikasikan pada flens atas dengan arah gravitasi. Gelagar pelat dengan panjang $3 \mathrm{~m}$ dimodelkan dalam analisis elemen hingga menggunakan prinsip simetri sehingga panjang yang dimodelkan adalah 1.5 m, seperti pada Gambar 1 .

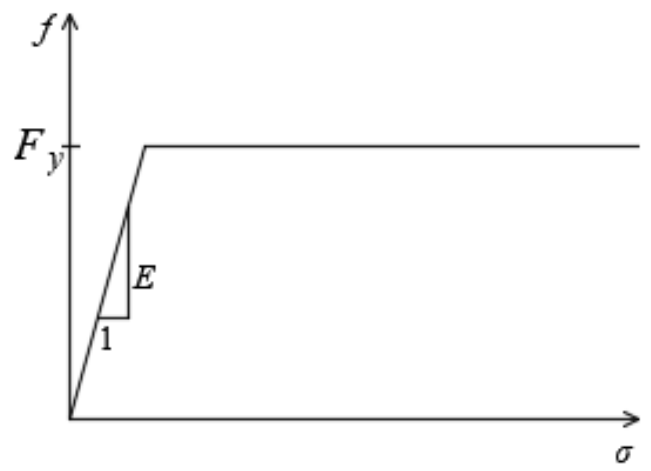

Gambar 2. Kurva Tegangan-Regangan Material Elastic Perfectly Plastic

Tumpuan sendi rol pada gelagar pelat dengan panjang $3 \mathrm{~m}$ dimodelkan sebagai sendi pada salah satu sisi dan jepit rol pada sisi lainnya (prinsip simetri).

Arah sumbu global ditunjukkan dalam Gambar 3 dengan sumbu X adalah arah lateral, sumbu Y adalah arah transversal, dan sumbu $Z$ adalah arah longitudinal. Tumpuan sendi dimodelkan sebagai baseplate dengan kekangan peralihan nodal (nodal displacement restraint) selebar flens dan sepanjang $160 \mathrm{~mm}$ dalam arah sumbu Z. Translasi nodal ini ditahan dalam arah X, Y, dan Z. Pada flens atas tumpuan sendi, translasi nodal ditahan dalam arah X. Untuk tumpuan jepit rol, translasi penampang ditahan dalam arah $\mathrm{X}$ dan $\mathrm{Z}$.

Analisis elemen hingga menggunakan automatic mesh generation. Ukuran elemen dibatasi maksimal $20 \mathrm{~mm}$. Berdasarkan studi awal pada penelitian ini, ukuran elemen tersebut mampu menggambarkan gradien tegangan yang terjadi.

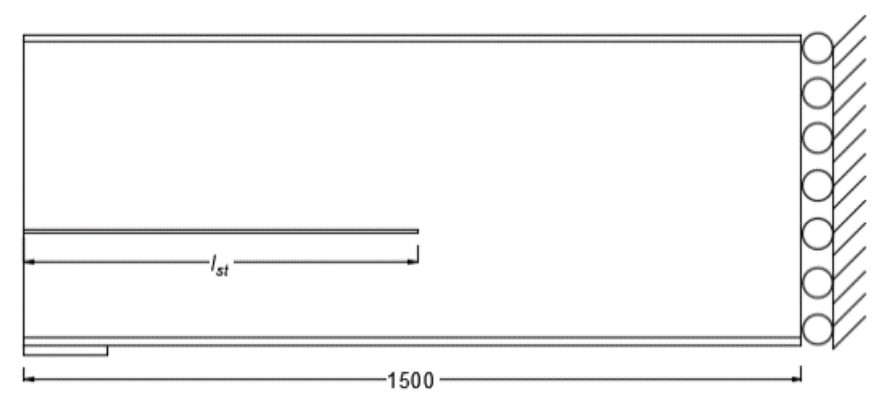

Gambar 1. Geometri Gelagar Pelat (satuan dalam mm) 

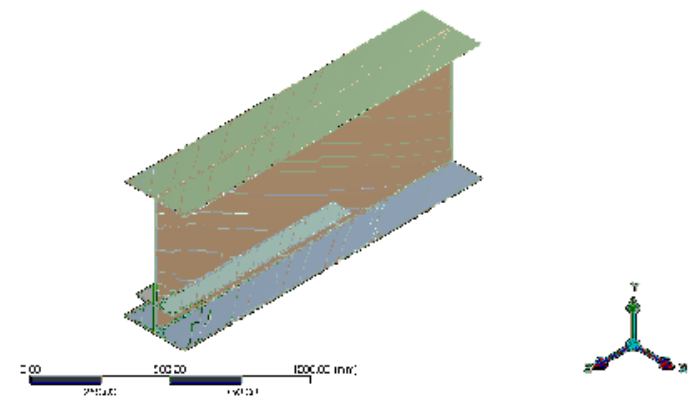

Gambar 3. Arah Sumbu Global Pemodelan

\subsection{Analisis Tekuk Linear}

Analisis tekuk linear yang dimaksud di dalam studi ini adalah analisis nilai eigen. Analisis ini memperhitungkan efek orde kedua di dalam matriks kekakuan. Beban tekuk (nilai eigen) dan deformasi tekuk (vektor eigen) didapat dari analisis dengan membuat determinan matriks kekakuan sama dengan nol[7]. Beban tekuk yang didapat adalah titik batas pertama sebelum struktur menjadi tidak stabil. Sebagai contoh, gelagar pelat diberi beban sebesar $10 \mathrm{kN}$, kemudian dihasilkan faktor beban sebesar 26,5160. Dengan demikian beban kritisnya adalah 26,5160 x $10 \mathrm{kN}$ yaitu $265,16 \mathrm{kN}$. Deformasi tekuk diperlukan untuk menginisiasi tekuk pada analisis tekuk nonlinear. Contoh deformasi tekuk yang terjadi dapat dilihat pada Gambar 4.

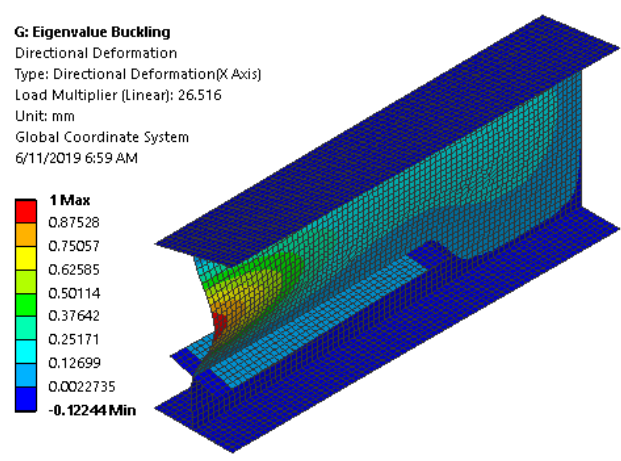

Gambar 4. Deformasi Tekuk Linear Arah Lateral

\subsection{Analisis Tekuk Nonlinear}

Analisis tekuk nonlinear digunakan agar dapat merekam riwayat terjadinya tekuk. Analisis nonlinear terjadi akibat ketidaklinearan geometri dan ketidaklinearan material[8]. Apabila struktur tidak diberi deformasi tekuk awal, struktur tidak akan mengalami tekuk pada saat dibebani dalam bidang gambar[7]. Itulah sebabnya struktur diberi ketidaksempurnaan geometri awal. Ketidaksempurnaan ini diambil dari bentuk terdeformasi analisis tekuk linear dan diaplikasikan dengan memanfaatkan fasilitas UPGEOM pada ANSYS. Bentuk tersebut diberi nilai amplitudo yang cukup kecil.
Nilai tersebut diambil sebesar $\frac{\sqrt{b_{1} l_{s t}}}{500}$ yang berada di rentang $h / 10000$ dan $h / 100[7]$. Besaran $b_{1} l_{s t}$ digunakan untuk mewakili luas pelat di bawah pengaku longitudinal.

Ketidaklinearan material dimodelkan sesuai dengan kurva tegangan-regangan pada Gambar 2. Kriteria kelelehan yang dipakai adalah kriteria Von Mises[9], yang berarti apabila tegangan Von Mises di suatu titik sudah mencapai tegangan leleh baja yang digunakan, yaitu $250 \mathrm{MPa}$, maka titik tersebut mengalami kelelehan.

Pada analisis tekuk nonlinear, digunakan metode step-bystep integration. Pada studi ini, digunakan metode kontrol beban, sehingga beban diaplikasikan secara inkremental. Pemberian beban tersebut dibagi menjadi 100 substeps.

\section{Hasil dan Pembahasan}

Model elemen hingga yang dibuat pada ANSYS diverfikasi menggunakan persamaan lipat web tanpa pengaku yang terdapat di AISC 360-16. Persamaan lipat web untuk daerah tumpuan yang dipakai adalah untuk $l_{b} / d>0,2$, seperti pada Persamaan 1.

$$
R_{n}=0,40 t_{w}^{2}\left[1+\left(\frac{4 l_{b}}{d}-0,2\right)\left(\frac{t_{w}}{t_{f}}\right)^{1.5}\right] \sqrt{\frac{E F_{y w} t_{f}}{t_{w}}} Q_{f}
$$

Beban maksimum yang dapat dipikul saat analisis linear adalah 153,33 kN. Kemudian dilakukan analisis nonlinear dan beban yang dapat diterima adalah $144 \mathrm{kN}$. Kekuatan lipat web hasil perhitungan dengan Persamaan 1 adalah 142,9 $\mathrm{kN}$. Persamaan lipat web AISC diturunkan dari uji eksperimental yang memungkinkan terjadinya leleh pada saat lipat web terjadi sehingga persamaan tersebut dibandingkan dengan hasil analisis tekuk nonlinear pada studi ini. Persentase perbedaan antara analisis tekuk nonlinear dan persamaan AISC sangat kecil, yaitu $0,77 \%$ sehingga pemodelan dengan elemen hingga sudah baik.

Gambar 5 menunjukkan faktor perbesaran kekuatan lipat web balok dengan pengaku longitudinal. Faktor tersebut didapat dari hasil analisis nonlinear kekuatan lipat web dengan pengaku longitudinal $\left(P_{s t}\right)$ dibagi dengan kekuatan lipat web tanpa pengaku longitudinal yang dihitung dengan menggunakan Persamaan $1\left(P_{n s t}\right)$. Pada saat lokasi vertikal di $0,2 h$ dan pengaku longitudinal bertambah panjang (relatif terhadap 0,5l) dari 0,2 hingga 0,4, faktor perbesaran beban maksimum lipat web mengalami peningkatan, kemudian dari 0,4 hingga 1 , faktor perbesaran tersebut mengalami penurunan, demikian juga terjadi pada lokasi vertikal di $0,4 h$, $0,5 h$, dan $0,6 h$. Pada saat lokasi vertikal di $0,3 h$, terjadi peningkatan faktor perbesaran kekuatan lipat web ketika panjang pengaku longitudinal meningkat dari 0,2 hingga 0,6 dan ketika diperpanjang lagi faktor perbesarannya menurun. 
Dengan demikian, panjang pengaku longitudinal yang optimum di panjang relatif terhadap $0,5 l$ adalah sebesar 0,4 hingga 0,6 .

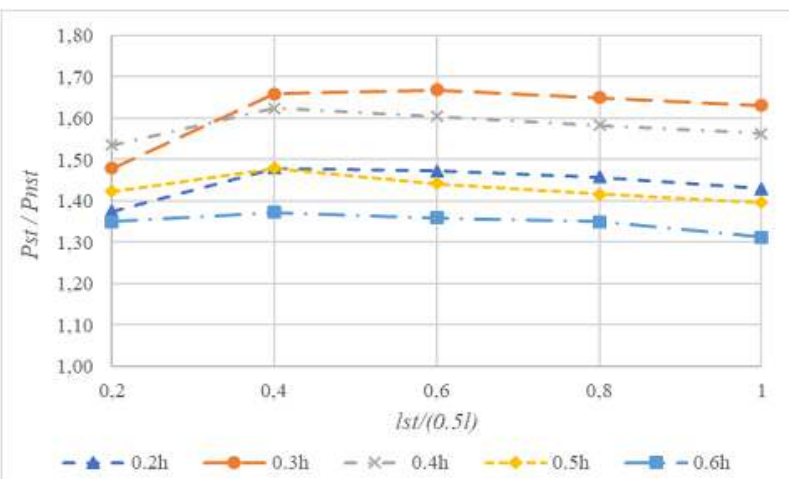

Gambar 5. Faktor Perbesaran Kekuatan Lipat Web Balok dengan Pengaku Longitudinal

Dari Gambar 5, terlihat bahwa faktor perbesaran kekuatan lipat web yang paling optimum adalah di lokasi vertikal $0,3 h$ dengan faktor perbesaran maksimum sebesar 1,6688. Ketika lokasi vertikal berubah dari $0,2 h$ ke $0,3 h$, faktor perbesaran mengalami peningkatan sedangkan dari $0,3 h$ hingga $0,6 h$, faktor perbesaran mengalami penurunan. Hal ini berarti peningkatan lokasi vertikal setelah $0,3 h$ tidak lagi efektif karena lokasinya semakin jauh dari beban terpusat di tumpuan. Hal tersebut dapat diamati pada deformasi akibat tekuk yang terjadi seperti pada Gambar 6.

Gambar 6 menunjukkan panjang pengaku longitudinal tetap, namun lokasi vertikalnya bervariasi. Ketika gelagar pelat diberi pengaku, bentuk terdeformasi akibat beban tekan akan menjadi kurvatur ganda. Perpindahan lokasi vertikal ini berpengaruh pada bentuk deformasi lateral balok. Ketika pengaku longitudinal terletak pada $0,2 h, 0,3 h$, dan $0,4 h$, kelengkungan pelat di atas pengaku lebih besar daripada yang di bawah. Ketika pengaku longitudinal terletak pada $0,5 h$, kelengkungan pelat di atas dan di bawah pengaku sama. Ketika pengaku longitudinal terletak pada $0,6 h$, kelengkungan pelat di atas lebih kecil daripada yang di bawah pengaku. Karena lokasi beban terpusat berada di bawah, maka pengaku akan lebih bekerja secara optimum ketika posisinya relatif lebih dekat ke flens bawah namun tidak dapat terlalu dekat ke flens bawah karena hal ini akan menyebabkan segmen web di atas pengaku lebih mudah mengalami tekuk. Hal ini terlihat pada kontur tegangan di Gambar 7. Tegangan Von Mises berkembang dari area dekat tumpuan dimana beban terpusat terjadi. Kemudian tegangan tersebut disebarkan oleh pengaku longitudinal. Pada saat substep sebesar 0,6, tegangan Von Mises yang mencapai batas leleh terjadi. Setelah substep tersebut, tegangan leleh menyebar ke area yang lebih luas.
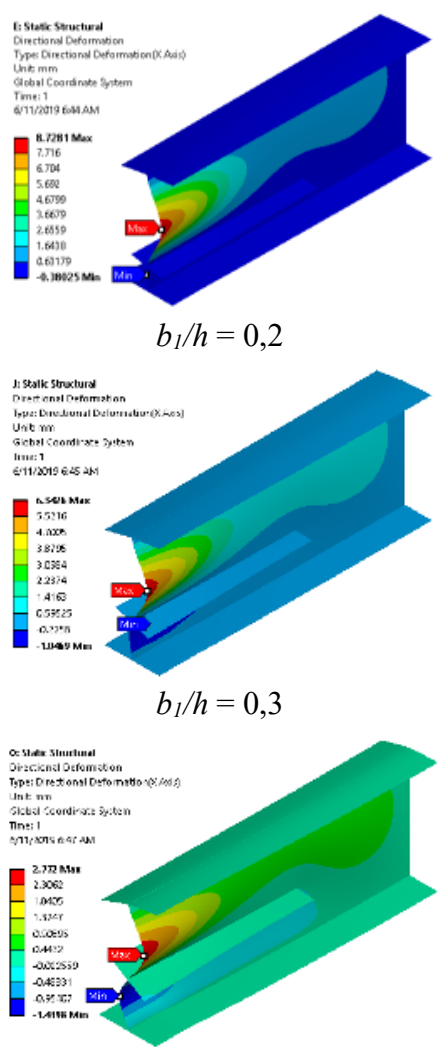

$b_{1} / h=0,4$

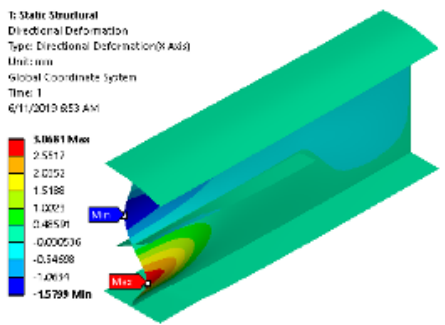

$b_{1} / h=0,5$

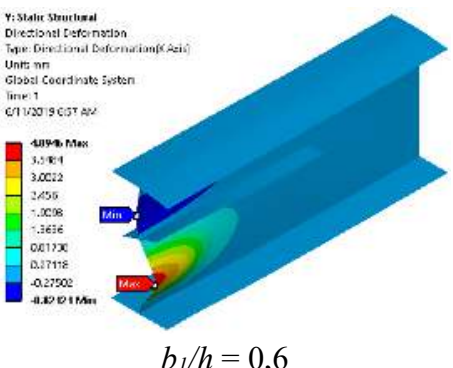

Gambar 6. Deformasi Tekuk Nonlinear dengan Pengaku Longitudinal $l_{s t} /(0,5 l)=0,4$. 


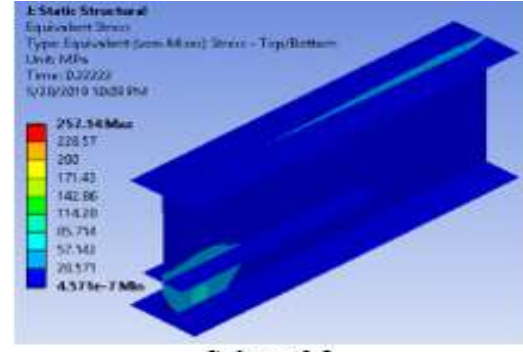

Substep 0.2
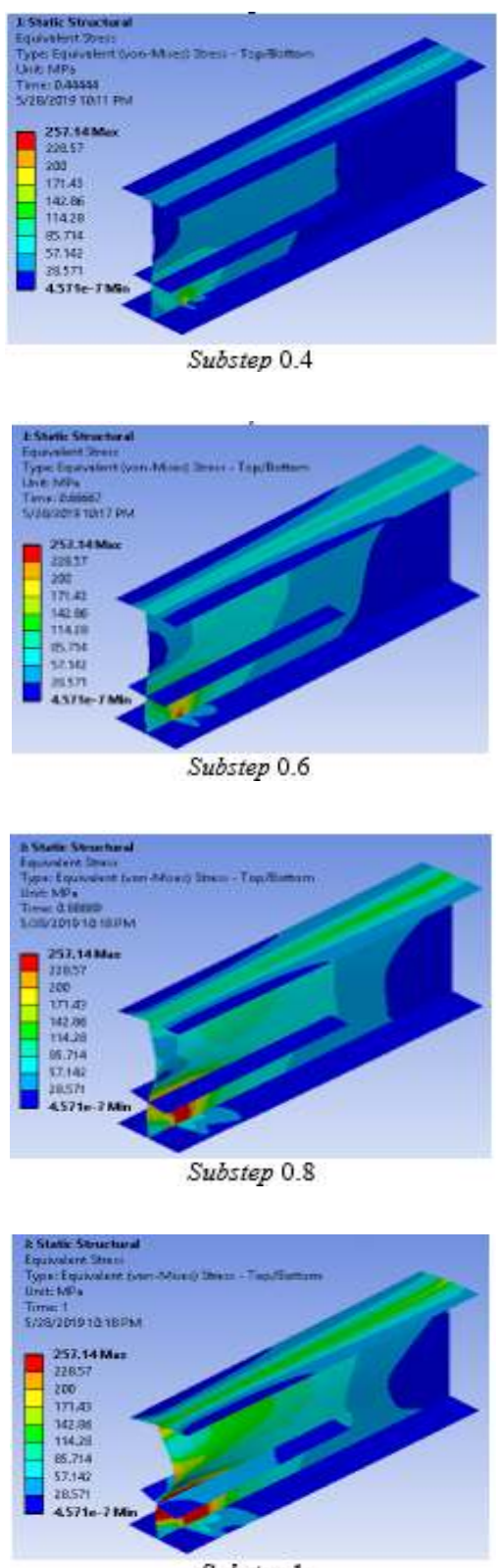

Substep 1

Gambar 7. Penyebaran Daerah Leleh pada Saat Peningkatan Beban
Analisis regresi dengan menggunakan data pada Tabel 1 dilakukan untuk memprediksi kekuatan lipat web balok baja dengan pengaku longitudinal. Dengan meninjau Gambar 5, dapat diperkirakan bahwa persamaan yang akan dihasilkan polinomial berderajat tiga. Untuk menyederhanakan persamaan tersebut, dilakukan stepwise regression (regresi bertatar) [10]. Faktor perbesaran kekuatan lipat web balok dengan pengaku longitudinal hasil analisis elemen hingga $\left(C_{s t}=\right.$ $\left.P_{s t} / P_{n s t}\right)$ dengan variasi lokasi vertikal dan panjang dibuat persamaan regresinya. Variasi lokasi vertikal didefinisikan dengan variabel $r_{l}=b_{1} / h$, sedangkan variasi panjang didefinisikan dengan variabel $r_{2}=l_{s t} /(0.5 l)$. Persamaan yang diperoleh adalah Persamaan 2, dengan koefisien determinasi Rsq $92,21 \%$ sehingga persamaan tersebut sudah cukup akurat.

$C_{s t}=-0.294+13.57 r_{1}+0.523 r_{2}-32.34 r_{1}^{2}$

$-0.421 r_{2}^{2}+23.2 r_{1}^{3}$

Persamaan 3 digunakan untuk memprediksi kekuatan lipat web balok dengan pengaku longitudinal.

$P_{s t}=C_{s t} P_{n s t}$

Persamaan 2 diplot ke dalam grafik 3 dimensi seperti pada Gambar 8. Untuk mendapatkan lokasi vertikal dan panjang yang optimum, turunan parsial Persamaan 2 terhadap $r_{l}$ dan $r_{2}$ disamakan dengan nol sehingga diperoleh $r_{l}$ $=0,32$ dan $r_{2}=0,62$.

Tabel 1 menunjukkan persentase perbedaan analisis nonlinear dengan hasil regresi. Walaupun persentase perbedaan terletak dalam rentang antara $-3,37 \%$ dan $+6,85 \%$, namun secara menyeluruh persamaan regresi tersebut sangat baik, sebagaimana ditunjukkan dengan koefisien determinasi yang mendekati 1,0 .

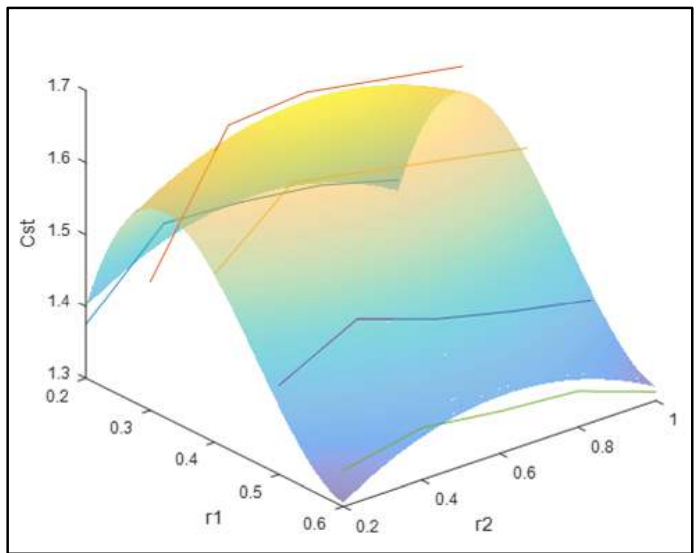

Gambar 8. Plot Persamaan 2 dan Hasil Analisis Nonlinear Tampak 3D 
Tabel 1. Data yang Digunakan untuk Regresi dan Perbedaan antara Analisis Nonlinear dan Persamaan Regresi

\begin{tabular}{ccccc}
\hline$b_{1} / h$ & $l_{s t}(0,5 l)$ & $P_{s t} / P_{n s t}$ & $C_{s t}$ & $\begin{array}{c}\text { Perbedaan } \\
(\%)\end{array}$ \\
\hline 0,2 & 0,2 & 1,38 & 1,40 & 1,80 \\
0,2 & 0,4 & 1,48 & 1,45 & $-1,71$ \\
0,2 & 0,6 & 1,47 & 1,47 & 0,14 \\
0,2 & 0,8 & 1,46 & 1,46 & 0,18 \\
0,2 & 1 & 1,43 & 1,41 & $-1,06$ \\
0,3 & 0,2 & 1,48 & 1,58 & 6,85 \\
0,3 & 0,4 & 1,66 & 1,63 & $-1,51$ \\
0,3 & 0,6 & 1,67 & 1,66 & $-0,82$ \\
0,3 & 0,8 & 1,65 & 1,64 & $-0,50$ \\
0,3 & 1 & 1,63 & 1,59 & $-2,23$ \\
0,4 & 0,2 & 1,53 & 1,53 & $-0,17$ \\
0,4 & 0,4 & 1,63 & 1,59 & $-2,39$ \\
0,4 & 0,6 & 1,60 & 1,61 & 0,15 \\
0,4 & 0,8 & 1,58 & 1,59 & 0,63 \\
0,4 & 1 & 1,56 & 1,55 & $-1,03$ \\
0,5 & 0,2 & 1,42 & 1,39 & $-2,10$ \\
0,5 & 0,4 & 1,48 & 1,45 & $-2,12$ \\
0,5 & 0,6 & 1,44 & 1,47 & 1,79 \\
0,5 & 0,8 & 1,42 & 1,45 & 2,70 \\
0,5 & 1 & 1,40 & 1,41 & 0,87 \\
0,6 & 0,2 & 1,35 & 1,30 & $-3,37$ \\
0,6 & 0,4 & 1,37 & 1,36 & $-0,99$ \\
0,6 & 0,6 & 1,36 & 1,38 & 1,51 \\
0,6 & 0,8 & 1,35 & 1,37 & 1,17 \\
0,6 & 1 & 1,31 & 1,32 & 0,48 \\
\hline & & & &
\end{tabular}

\section{Simpulan}

Panjang dan lokasi vertikal pengaku longitudinal berpengaruh pada kekuatan lipat web balok baja di tumpuan. Analisis elemen hingga menghasilkan persamaan regresi yang dapat digunakan untuk memprediksi kekuatan lipat web balok baja dengan pengaku longitudinal. Dengan menggunakan persamaan regresi tersebut, lokasi vertikal optimum terletak pada rasio $b_{1} / h$ sebesar 0,32 dan panjang pengaku longitudinal optimum adalah pada rasio $l_{s t}(0,5 l)$ sebesar 0,62 . Kekuatan lipat web baja dengan menggunakan kedua rasio optimum tersebut adalah 1,66 kali kekuatan lipat web baja tanpa pengaku.

\section{Daftar Pustaka}

[1] T. M. Murray, W. S. Easterling, and C. L. Robertswollmann, "Nonlinear Finite Element Analyses of
The End Web Crippling Strength Of W-Shape Steel Beams By Nonlinear Finite Element Analyses Of The End Web Crippling Strength Of W-Shape Steel Beams," no. August, 2002.

[2] T. ROBERTS, "Slender Plate Girders Subjected To Edge Loading," Proc. Inst. Civ. Eng., 2007.

[3] C. A. Graciano and B. Edlund, "Nonlinear FE analysis of longitudinally stiffened girder webs under patch loading," J. Constr. Steel Res., vol. 58, no. 9, pp. 1231-1245, 2002.

[4] C. G. Salmon and J. E. Johnson, "Steel Structures: Design and Behaviour." 1995.

[5] N. Loaiza, C. Graciano, and R. Chacón, “Web crippling strength of longitudinally stiffened steel plate girder webs subjected to concentrated loading," Proc. Annu. Stabilitiy Conf. Struct. Stab. Res. Counc., no. 2011, pp. 1-14, 2017.

[6] ANSI/AISC 360-16, "Specification for Structural Steel Buildings ANSI/AISC 360-16," Aisc, p. 676, 2016.

[7] R. M. Akbar and B. Suryoatmono, "Numerical study of inelastic buckling behavior of rectangular steel plates with circular openings under shear forces," MATEC Web Conf., vol. 258, p. 05026, 2019.

[8] H.-H. Lee, "Chapter 6: Surface Models," Finite Element Simulations with ANSYS Work. 17, 2017.

[9] M. H. Sadd, Elasticity: Theory, applications, and numerics, third edition. 2014.

[10] J. O. Rawlings, S. G. Pantula, and D. A. Dickey, Applied Regression Analysis: A Research Tool, Second Edition, vol. 18, no. 1. 1998. 